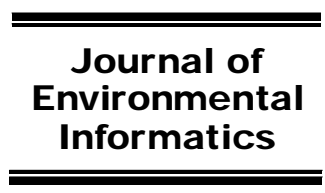

www.iseis.org/jei

\title{
Editorial: Wetland Informatics - Ecological Network Design and Implementation
}

\author{
Guest Editor: Z. F. Yang* \\ State Key Laboratory of Water Environment Simulation, School of Environment, Beijing Normal University, Beijing 100875, China
}

Natural influences and human actions continually bring about changes in wetland ecosystems (Katsaros et al., 2008). It is becoming increasingly clear that species are less able to adapt to natural changes at local and regional scales when those changes are compounded by human-caused alterations (UNEP, 1995). To stop and reverse the loss and degradation of wetlands, it's necessary to provide scientific and statistically reliable data that can be used in modeling and decision making related to the corresponding environmental problems on the ecosystem. Therefore, this special issue is aimed to share information about wetlands with various users and highlight conservation issues of relevance to wetland community of professionals, managers, environmentalists and other stakeholders.

From August 27 to 29, 2010, we co-organized the biennial international conference on Ecological Informatics and Ecosystem Conservation with the International Society for Environmental Information Sciences (http:// www.iseis.org/). The sustainable development of the wetland ecosystem created the need to lay a sound scientific basis for wetland conservation by gathering, synthesizing and disseminating relevant information on a local, national and international level. The symposia organized at this conference were a good reflection of the topics on how to make effective use of the wetland ecological network, which provided a basis for comparable and systematic information on the trends and status of wetlands. Attention is to be paid to promoting the results obtained by the application of the system and transmitting them to policy makers, thus equipping them with the best available information for decision making regarding wetland management. It is also anticipated that the researchers in wetland conservation can make use of these tools effecttively to communicate, educate and raise public awareness of their own subject areas.

The paper by Recknagel (2013) presents case studies for analysis and synthesis of ecological data by means of

\footnotetext{
${ }^{*}$ Corresponding author. Tel.: +861058807951; fax: +8610 58807951. E-mail address: zfyang@bnu.edu.cn (Z. F. Yang).

ISSN: 1726-2135 print/1684-8799 online (C) 2013 ISEIS All rights reserved. doi:10.3808/jei.201300226
}

unsupervised artificial neural networks and hybrid evolutionary algorithms to assist in computational bioindication of wetland water quality and early warning of cyanobacteria blooms in lakes and reservoirs. Lei et al. (2013) used a rapid assessment approach to dynamically evaluate intertidal wetland sediments in the Deep Bay, South China in terms of monitored benthic macroinvertebrates. Li et al. (2013) comparatively analyzed three typical wetland ecosystems in the Huang-Huai-Hai (3H) Area, to clarify the similarities and differences of each pattern and process, and to explore its intrinsic correlation network mechanism. Su et al. (2013) explores the similarities and differences between Baiyangdian wetland in China and Mariager fjord in Denmark in terms of ecosystem characteristics, historical and cultural backgrounds of these social networks. Hao et al. (2013) employed a principal component analysis (PCA) method to identify the components that mainly affect water quality based on a large amount of water quality data of four typical wastewater reclamation treatment plants (WRTP) in northern China. Wu et al. (2013) analyzed and evaluated the suitability of potential habitat in GNR by using GIS based spatial network technology in order to get a comprehensive grasp of the habitat quality spatially. Chen et al. (2013) proposed "consistent comparative studies" via conducting a 112-region, 57-sector coupled systems ecological input-output network simulation for $\mathrm{CO}_{2}$ emission generated by fossil fuels combustion for the world economy in 2004, which is responsible for over half of the anthropogenic global warming effect according to the 100-year global warming potential. Yang and Chen (2013) employed the Ecopath software to establish two mass-balance ecosystem models before and after flow regulation in September 2009. The changes in trophic composition, flow processes, and other ecosystem network indices were compared.

The Guest Editor would like to express his high appreciation to the authors and reviewers for their great contribution to this special issue.

\section{References}

Chen, Z.M., Chen, G.Q., and Chen, B. (2013). Embodied Carbon Dioxide Emission by the Globalized Economy: A Systems Ecological Input-output Simulation. J. Environ. Inform., in press. 
Katsaros, P., Kapanidis, Y., and Mentis, A. (2008). Inventory, assessment and monitoring of Mediterranean Wetlands: The MedWet Web Information System User Manual. AUTH \& EKBY. MedWet publication.

Hao, R.X., Li, S.M., Li, J.B., Zhang, Q.K., and Liu, F. (2013) Water Quality Assessment for Wastewater Reclamation Using Principal Component Analysis. J. Environ. Inform., in press.

Lei, L., Sun, J.S., Borthwick, A.G.L., Fang, Y., and Ni, J.R. (2013) Dynamic Evaluation of Intertidal Wetland Sediment Quality in a Bay System. J. Environ. Inform., in press.

Li, A.N., Deng, W., Kong, B., Song, M.Q., Feng, W.L., Lu, X.N., and Lei, G.B. (2013). A Study on Wetland Landscape Pattern and Process in Huang-Huai-Hai (3H) Area, China. J. Environ. Inform., in press.

Recknagel, F. (2013). Current scope, case studies and future direc- tions of ecological informatics. J. Environ. Inform., in press.

Su, L.Y., Christensen, P., and Liu, J.L. (2013). Comparative Study of Water Resource Management Policies between China and Denmark. J. Environ. Inform., in press.

UNEP. (1995). Global Biodiversity Assessment. United Nations Environment Programme and Cambridge University Press. Cambridge, UK.

Wu, P.F., Liu, X.H., Shao, X.M., Zhu, Y., and Cai, Q. (2013). GIS Application in Evaluating the Potential Habitat of Giant Pandas in Guanyinshan Nature Reserve, Shaanxi Province. J. Environ. Inform., in press.

Yang, Y., and Chen, H. (2013). GIS Application in Assessing the Impacts of Flow Regulation on Trophic Interactions in a Wetland Ecosystem. J. Environ. Inform., in press. 